\title{
Hepatitis aguda viral durante el embarazo
}

\author{
Enrique Valdés R., Alvaro Sepúlveda M., Paula Candia P., Karina Lattes A.
}

\section{Acute viral hepatitis during pregnancy}

Acute hepatitis has a very low incidence disease during pregnancy. However, it may be an important cause of jaundice during gestation which in cases of viral etiology can have a very high morbidity and mortality risk to the mother and the fetus. The purpose of this review is to update the available knowledge regarding viral hepatitis during pregnancy including description of the main etiologies, transmission route, maternal-fetal risk and possible management.

Key words: Viral hepatitis, pregnancy, vertical transmission, vaccine.

Palabras clave: Hepatitis viral, embarazo, transmisión vertical, vacuna.

\author{
Hospital Clínico Universidad \\ de Chile, Santiago. \\ Unidad de Medicina Fetal (EVR) \\ Departamento de Obstetricia y \\ Ginecología (ASM, KLA). \\ Universidad Mayor, Santiago, \\ Chile. \\ Facultad de Medicina (PCP) \\ Recibido: 23 de abril de 2009 \\ Aceptado: 24 de septiembre de \\ 2010 \\ Correspondencia a: \\ Enrique Valdés R. \\ evaldes@vtr.net
}

\section{Introducción}

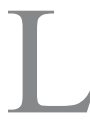
a hepatitis aguda es una entidad que puede ser producida por diversos agentes siendo más frecuente la infección debida a diversos tipos de virus hepatotropos conocidos (A, B, C, D y E). Ocasionalmente el agente causal es diferente, destacando entre ellos: virus de Epstein-Barr, citomegalovirus, virus de la fiebre amarilla, rubéola, adenovirus y virus herpes simplex $)^{1,2}$.

Durante el embarazo es fundamental hacer el diagnóstico diferencial etiológico de la hepatitis aguda, sumando a las causas virales, las etiologías autoinmunes y hepatopatías propias del embarazo como el síndrome de HELLP. ${ }^{3}$

El cuadro clínico de la hepatitis viral aguda (HVA) durante la gestación se presenta de modo semejante al de una paciente no embarazada, sin importar el agente causal, a través de cuatro etapas: período de incubación; fase pre-ictérica sintomática; fase ictérica sintomática y fase de convalecencia ${ }^{1}$.

La siguiente revisión expone las características virales, el impacto clínico en la mujer embarazada, el riesgo de transmisión vertical (TV) y el manejo perinatal de los diversos tipos de virus hepatitis.

\section{Virus de hepatitis A}

Generalidades: pertenece a la familia Picornavirus y contiene un ARN de tamaño pequeño (27 a $30 \mathrm{~nm}$ ). Se caracteriza por no producir hepatitis crónica ni estado de portador ${ }^{1,3}$.

Epidemiología: se estima una incidencia mundial de 1,5 millones de casos nuevos ${ }^{2,4}$, teniendo una relación directa con el nivel socioeconómico del país. En Chile actualmente se presenta como una endemia media, lo que refleja un mayor contagio en niños mayores de cinco años, adolescentes y adulto joven. Este fenómeno se ha visto reflejado en las últimas décadas, con incidencias cada vez menores en niños y aumento progresivo en adolescentes ${ }^{4}$. La tasa de mortalidad es relativamente baja, con cifras que van de 0,1 a $0,6 \%{ }^{1,5}$. La incidencia descrita en mujeres embarazadas es cercana a $1 / 1000$, mientras que en la población general de nuestro país alcanza cifras de $70 \mathrm{x}$ 100.000 habitantes ${ }^{4}$.

Vía de contagio: ingestión de agua o alimentos contaminados con heces humanas (transmisión fecal-oral).

Periodo de incubación: de 7 a 14 días, pudiendo prolongarse hasta 6 semanas. Es el período de mayor excreción del virus en las heces (Tabla 1) 1,3.

Manifestaciones clínicas: generalmente es asintomática y autolimitada. Cuando es sintomática se asocia a ictericia y síntomas inespecíficos como fiebre, malestar general y dolor abdominal. La clínica depende de la edad al contagio, siendo sintomática en $\sim 30 \%$ si es adquirida durante la niñez, mientras que si es adquirida en la adultez es sintomática en $\sim 80 \%$ de los casos ${ }^{6}$. Otra complicación poco frecuente es la hepatitis fulminante, describiéndose incidencias de hasta $1 \%$ de los infectados ${ }^{3}$.

Hepatitis $A$ en el embarazo: a pesar de ser la causa más frecuente de hepatitis en la población general, es una entidad poco frecuente en la mujer embarazada ${ }^{5,7}$, no habiendo evidencias que apoyen la existencia de un mayor riesgo de complicaciones graves, como la hepatitis fulminante.

Transmisión vertical (TV): a pesar de que se ha descrito que el virus es capaz de atravesar la placenta, no ha podido demostrarse infección clínica en recién nacidos de madres con la enfermedad activa, independiente del trimestre de 
Tabla 1. Características generales de la hepatitis causada por distintos virus hepatotropos

\begin{tabular}{|c|c|c|c|c|c|}
\hline Característica & Hepatitis A & Hepatitis B & Hepatitis C & Hepatitis D & Hepatitis E \\
\hline Vía de transmisión & Fecal-oral & Parenteral, sexual & Parenteral, sexual & Parenteral, sexual & Fecal-oral \\
\hline Período de incubación & 2 a 6 semanas & 4 a 26 semanas & 2 a 26 semanas & 4 a 7 semanas & 2 a 8 semanas \\
\hline Aguda / crónica & Aguda & Aguda o crónica & Aguda o crónica & Aguda o crónica & Aguda \\
\hline Transmisión vertical & No & Sí & $\begin{array}{l}\text { Sí (excepcional, mujeres } \\
\text { con factores de riesgo) }\end{array}$ & No & Sí \\
\hline Evolución adversa en el embarazo & Muy poco frecuente & Muy poco frecuente & Muy poco frecuente & No & Sí \\
\hline
\end{tabular}

la primoinfección, la vía del parto o de la mantención de la lactancia materna ${ }^{3,5,7}$. Ante un recién nacido con sospecha clínica de hepatitis y/o madre con diagnóstico confirmado, debe determinarse IgM específica. De ser ésta negativa, mantener los controles habituales, debido a la baja frecuencia reportada de $\mathrm{TV}^{7}$.

Diagnóstico en la mujer embarazada: ante la sospecha clínica en la madre, el diagnóstico debe confirmarse con la detección en sangre de inmunoglobulina $M$ anti virus de hepatitis A (IgM anti VHA) y transaminasas elevadas ${ }^{1,3}$. La seroconversión de IgG se produce desde las 10 a 12 semanas de la primoinfección, reflejando la ausencia del cuadro agudo y la inmunidad futura de la paciente.

Prevención y tratamiento: la prevención de la infección por VHA se basa en medidas higiénicas y una correcta manipulación de alimentos ${ }^{2,8}$. En el período neonatal es fundamental reforzar estas medidas si la madre padece la enfermedad, ya que esta puede transmitirla por contacto. La lactancia materna no ha demostrado ser una vía de contagio, por lo tanto, no está contraidicada ${ }^{3}$.

Actualmente existen diversas vacunas creadas en base a virus inactivo que pueden utilizarse con seguridad en el embarazo, ya que no han demostrado ser teratogénicas (Tabla 2) $)^{9,10}$. Con respecto a su uso en el hijo de madre seropositiva, y a pesar que actualmente se ha utilizado desde los 12 meses de vida sin complicaciones reportadas $^{11}$, no se ha confirmado su inocuidad en menores de dos años; el contener virus inactivado, permite presuponer,

\section{Tabla 2. Vacunas para prevención de hepatitis A y B en el embarazo ${ }^{8}$}

\section{Vacuna}

Hepatitis A (virus inactivado)

Hepatitis B (HBsAg de origen recombinante)

\section{Seguridad en el embarazo}

Bajo riesgo fetal (faltan estudios que confirmen inocuidad sobre el feto)

Sin afección fetal demostrada

\section{Indicación}

Por indicación médica en mujeres con riesgo alto de contagio (residencia en zonas de prevalencia elevada)

Con factores de riesgo:

- Uso de drogas ev ilícitas

- Inicio de hemodiálisis

- Prostituta

- Residente de país con endemia alta
HBsAg: antígeno de superficie por otra parte, una razonable seguridad en esta edad . Bajo el año de edad no se recomienda su uso por interferir con la transferencia pasiva de anticuerpos desde la madre.

\section{Virus de hepatitis B}

Generalidades: pertenece a la familia Hepadnavirus, con genoma ADN circular, de aproximadamente $42 \mathrm{~nm}$ de diámetro. ${ }^{12}$ Dentro de las diversas proteínas que codifica, son importantes para el diagnóstico de esta enfermedad: el antígeno central o core ( $\mathrm{HBcAg})$, el antígeno e (HBe$\mathrm{Ag})$ y el antígeno de superficie (HBsAg) $)^{1,3,12}$. Este virus tiene la capacidad de evolucionar a enfermedad aguda, hepatitis crónica, cirrosis, carcinoma hepático o hepatitis fulminante ${ }^{1}$.

Epidemiología: la hepatitis B es un problema global, se reportan entre 300 a 350 millones ${ }^{1,3}$ de portadores crónicos en el mundo, siendo algunos países latinoamericanos los de más alta prevalencia en la población general (HBsAg $(+)$ entre 0,4 y $20 \%)^{12,13}$, a diferencia de países desarrollados como Estados Unidos de Norteamérica (E.U.A.) cuyas cifras son cercanas a $0,1 \%{ }^{12}$. En Chile, el año 2005 se describieron tasas de 1,2 por 100.000 habitantes de acuerdo a los datos recogidos a través de las notificaciones al Ministerio de Salud, con una prevalencia de $0,25 \%$ en donantes de sangre ${ }^{13}$.

Vía de contagio: preferentemente se adquiere por contacto con sangre contaminada (vía sexual, transfusión de productos sanguíneos, TV). Sin embargo, también puede ser contagiada por secreciones como semen, sudor y leche materna, no así por las heces. En regiones endémicas la forma más frecuente de contagio es por TV, principalmente durante el parto. En países con incidencias bajas, la principal vía de contagio es la sexual por lo que la primoinfección es más frecuente en el adulto ${ }^{3,12}$. En niños, al excluir la TV, la principal causa de contagio es por contacto con un familiar afectado y por manipulación de agujas y jeringas contaminadas ${ }^{12}$.

Período de incubación: posee un amplio rango que va desde las 4 a las 26 semanas con una media de 90 días (Tabla 1) ${ }^{14}$, siendo sintomático sólo $30 \%$ de los infectados ${ }^{1,3}$. 
Manifestaciones clínicas: puede presentarse con síntomas hepáticos y extra-hepáticos una vez que el HBsAg alcanza sus niveles más altos. En el primer caso se caracteriza por ictericia, fiebre, malestar general, anorexia y dolor abdominal, mientras que en el segundo puede presentar rash cutáneo, artritis, edema angioneurótico, glomerulonefritis aguda, vasculitis y linfadenopatías. Los síntomas hepáticos son los clásicamente descritos. Generalmente las manifestaciones extra-hepáticas se asocian a hepatitis crónica, pero también pueden presentarse en asociación a cuadros agudos, siendo esto último excepcional. Afortunadamente, $90 \%$ de los pacientes adultos que presentan un cuadro agudo resolverán su cuadro espontáneamente, pero entre 5 y $10 \%$ evolucionará a portador crónico ${ }^{3}$ con el consecuente riesgo de desarrollar hepatitis crónica o carcinoma hepatocelular.

Hepatitis $B$ en el embarazo: la gestación no empeora el pronóstico de la enfermedad, excepto si está asociado a daño hepático crónico previo. Hasta hoy, no se ha demostrado un aumento de complicaciones antenatales como muerte intrauterina, aborto o anomalías congénitas ${ }^{12,15}$ con excepción de un mayor riesgo de parto prematuro en gestantes con un cuadro agudo.

Transmisión vertical: la transmisión de la infección al feto puede provenir de una madre infectada cursando con cuadro agudo o crónico, siendo la TV más frecuente en los casos de infección aguda adquirida en el último trimestre del embarazo, debido probablemente a la escasa producción de anticuerpos maternos que puedan ser transferidos al feto ${ }^{12}$; alcanza a tasas de infección de $80-90 \%$, en comparación con $10 \%$ si es transmitida en el primer trimestre. El periodo de mayor riesgo de TV ocurre durante el parto ( $85 \%$ de las infecciones perinatales) y sólo en 5 a $15 \%$ se produce durante el embarazo ${ }^{3,12}$. Es importante recordar que el riesgo de desarrollar portación crónica en aquellos niños infectados perinatalmente y que no recibieron inmunoprofilaxis llega hasta $90 \%$, cifra mucho más elevada que la infección en el adulto: Es entonces fundamental la administración de la inmunoglobulina específica dentro de las primeras 12 horas de vida (profilaxis pasiva) e iniciar simultáneamente con el programa de profilaxis activa- v.gr.: vacunación (1 dosis antes de 12 horas de vida), 1 a 2 meses y 6 meses de edad en hijos de aquellas madres que tienen infección activa o el diagnóstico de hepatitis crónica (Tabla 3$)^{12}$. El mayor riesgo de cronicidad de la infección antenatal viene determinada por la presencia de $\mathrm{HBeAg}$ materno, antígeno que es capaz de atravesar la barrera placentaria, no existiendo una respuesta inmunitaria adecuada en el feto $^{12}$. La presencia de $\mathrm{HBeAg}$ en suero materno es un marcador de infectividad, siendo más elevado en cuadros agudos más graves. Por el contrario, se ha comprobado una disminución a menos del 5\% de TV en madres HBeAg (-) HBsAg (+). Un estudio realizado el año 2003 comparó mujeres embarazadas HBsAg $(+)$ con $\mathrm{HBeAg}(+)$ y $(-)$. Junto con confirmar el paso de $\mathrm{HBeAg}$ transplacentario -fenómeno no demostrado hasta esa fecha- demostró que el HBeAg puede ser detectado en suero del lactante hasta los seis meses de vida a pesar de recibir profilaxis activapasiva al nacer ${ }^{16}$ (administración de vacuna anti VHB e inmunoglobulina específica, respectivamente), siendo esto un factor de riesgo del desarrollo de la cronicidad en $\mathrm{RN}$ infectados. Aunque se ha aislado el virus en la leche materna, no se ha demostrado infección por esta vía, por lo que la lactancia materna no está contraindicada.

Diagnóstico en la mujer embarazada: en la madre el diagnóstico es hecho por manifestaciones clínicas compatibles o factores de riesgo de infección (uso de drogas ev, promiscuidad sexual, contacto sexual con portador conocido de $\mathrm{VHB}$ ) asociado a parámetros serológicos. La presencia de $\mathrm{HBeAg}$ es de aparición y eliminación rápida por lo que lo más utilizado es la determinación de HBsAg en suero materno ${ }^{3,12}$, y la presencia de IgM anti $\mathrm{HBc}$ en casos agudos.

Prevención y tratamiento: la prevención puede llevarse a cabo con medidas generales y específicas. En el primer caso a través de estrategias destinadas a prevención de infecciones de transmisión sexual como el uso correcto del preservativo, evitar la promiscuidad, usar guantes si se va a tener contacto con sangre, evitar uso de drogas endovenosas, evitar el uso de instrumental reutilizable en caso de tatuajes, etc.

Las medidas específicas de prevención consisten en el uso de profilaxis pasiva-activa, siendo esto la medida más efectiva. La incorporación de la vacuna anti VHB en E.U.A., tanto en niños, como adolescentes y adultos logró una disminución de la incidencia de VHB de $67 \%{ }^{14}$ en un período de 10 años. En Chile actualmente el Programa Nacional de Inmunizaciones (PNI) contempla la vacunación anti VHB a los 2, 4 y 6 meses de vida.

La mujer embarazada seronegativa $((\mathrm{HBs} \mathrm{Ag}(-))$ puede recibir la vacuna con seguridad durante el embarazo, no demostrándose efectos deletéreos en el feto. Sin embargo, en nuestro país se administra la vacuna en mujeres no gestantes que lo soliciten, y no como parte de un programa.

Si la paciente es $\mathrm{HBsAg}(+)$ se recomienda determinar la determinación de $\mathrm{HBe} \mathrm{Ag}$, ya que su presencia aumenta el riesgo de TV desde 20 a $90 \%$ (Tabla 2 ) $^{9,17}$. Con respecto

Tabla 3. Infección por virus de hepatitis B y embarazo: Pronóstico postnatal según serología materna e inmunoprofilaxis neonatal

\begin{tabular}{|ll|}
\hline Serología materna & Hijo con inmunoprofilaxis pasiva-activa \\
\hline $\mathrm{HBeAg}(-) ; \mathrm{HBsAg}(+)$ & $\begin{array}{l}\text { Riesgo de infección crónica disminuye a }<1 \% \text {, disminuye el riesgo de } \\
\text { desarrollar hepatitis aguda y fulminante }\end{array}$ \\
$\mathrm{HBeAg}(+) ; \mathrm{HBsAg}(+)$ & $\begin{array}{l}\text { Riesgo de infección crónica disminuye a } 10 \text { a } 15 \% \text { (90\% cronicidad } \\
\text { sin profilaxis) }\end{array}$ \\
\hline
\end{tabular}


a este punto, diversos centros europeos recomiendan el tamizaje con detección de HBsAg en todas las mujeres embarazadas en el primer trimestre, repitiéndolo en el tercer trimestre solamente en aquellas con factores de riesgo. La vacuna se indica en toda paciente seronegativa durante o una vez finalizado el embarazo ${ }^{17}$. En el caso de mujeres embarazadas con infección activa adquirida antes o durante el embarazo (HBsAg $(+)$ con o sin $\mathrm{HBeAg}(+)$ ), existe evidencia que el uso de inmunoglobulina antiHB, asociado o no a lamivudina desde las 28 semanas de gestación, logra disminuir significativamente las tasas de infección intrauterina ${ }^{18,19}$. Un estudio reciente randomizó a mujeres embarazadas HBsAg $(+)$ a recibir desde las 32 semanas hasta las 4 semanas de puerperio tratamiento con lamivudina versus placebo asociado a vacunación e inmunoglobulina antiHB en los recién nacidos, demostrando una disminución significativa de títulos de HBsAg y ADN de VHB en suero de los niños que recibieron lamivudina intraútero $^{20}$, lo que apoya el uso de la inmunoglobulina y lamivudina en mujeres embarazadas infectadas, siendo protector para el feto y posteriormente para el RN.

En recién nacidos de madres $\mathrm{HBsAg}(+)$, la evidencia actual demuestra la utilidad del uso de la profilaxis pasivaactiva en la prevención del desarrollo de hepatitis $\mathrm{B}$, disminuyendo su incidencia en 50\%; al respecto es superior el beneficio de la combinación vacuna-inmunoglobulina específica que el uso de la vacuna sola ${ }^{20}$. La aplicación de inmunoglobulina antiHB durante el tercer trimestre de la gestación también demostró mejorar la respuesta inmune del recién nacido luego de recibir la vacuna ${ }^{21}$. Las dosis utilizadas en RN de madres $\mathrm{HBsAg}(+)$ se muestran en la Tabla $4^{12,14}$.

\section{Virus de hepatitis $\mathrm{C}$}

Generalidades: virus ARN perteneciente a la familia Flavivirus $^{1}$, de tamaño pequeño, con 6 genotipos mayores y múltiples subtipos, lo que asociado a una tasa de mutación alta lleva a una inmunidad ineficiente posterior a una infección activa y, por lo tanto, más difícil será confeccionar una vacuna. Es importante recordar que 60 a $85 \%$ de las personas infectadas por virus de hepatitis $\mathrm{C}$

Tabla 4. Profilaxis pasiva-activa de infección por virus de hepatitis B en niños según serología materna durante la gestación

\begin{tabular}{lcl}
$\begin{array}{l}\text { Serología } \\
\text { materna }\end{array}$ & Dosis vacuna & Esquema \\
$\mathrm{HBsAg}(+)$ & $10 \mu \mathrm{g}$ & $\begin{array}{l}\text { Administrar antes de } 12 \text { horas, } 1-2 \text { y } 6 \text { meses de vida (dosis } \\
\text { extra a los } 2-3 \text { meses en recién nacidos menores de } 2.000 \\
\end{array}$ \\
& $\begin{array}{l}\text { gramos) } \\
+ \\
\end{array}$ \\
& $0,5 \mathrm{ml}$ de lg anti-HB antes de 12 horas de nacer \\
\hline
\end{tabular}

Ig: inmunoglobulina
(VHC) desarrollan infección crónica.

Epidemiología: el VHC era el responsable de aproximadamente $90 \%$ de las hepatitis post- transfusiones. Desde el año 1992 en E.U.A. y, a partir del año 1996 en Chile, se implementó el estudio de VHC en todas las muestras almacenadas en los bancos de sangre, lográndose actualmente minimizar el riesgo de infección a menos de 1 por 100.000 unidades transfundidas ${ }^{1,3,17}$. La prevalencia de infección por $\mathrm{VHC}$ en países industrializados es de aproximadamente 0,2 a $2 \%{ }^{1,3}$, alcanzando en regiones de alta incidencia (Asia) valores cercanos a $12 \%$, lo que se traduce en 170 millones de infectados por VHC en el mundo ${ }^{22}$. En Chile se describen prevalencias en donantes de sangre de 0,22 a $0,3 \%{ }^{13}$. En mujeres en edad fértil la prevalencia en E.U.A. es de aproximadamente $1 \%{ }^{23}$. En países desarrollados la hepatitis C es la principal etiología de hepatopatía crónica en niños, infección que previo al cribado en bancos de sangre se transmitía por transfusiones, pero actualmente es adquirida mayoritariamente por vía vertical ${ }^{24}$. Un estudio reciente demostró que la infección por VHC es más frecuente que la infección por VHB en la población femenina no embarazada, situación que se invierte en las gestantes ${ }^{22}$. En mujeres embarazadas portadoras de VIH en E.U.A., la co-infección con VHC alcanza cifras que varían desde 17 a $54 \%{ }^{25}$, valores muy por sobre las gestantes sin infección por $\mathrm{VIH}$, quienes presentan una incidencia de $1 \%$.

Vía de contagio: la principal vía de contagio es por transfusión sanguínea y muy ocasionalmente por vía sexual (especialmente relacionada a promiscuidad sexual). En niños, la principal vía de contagio es por $\mathrm{TV} ; 5$ a 6\% de las madres con la infección por VHC la transmiten si en ellas está presente el ARN viral durante el parto. La co-infección con VIH ha sido asociada con un mayor riesgo de transmitir el VHC al RN.

Período de incubación: se describen períodos de 2 a 26 semanas, con un promedio de 30 a 60 días ${ }^{1,25}$ (Tabla 1).

Manifestaciones clínicas: la infección frecuentemente es asintomática (65 a 75\%); sin embargo, el cuadro clínico puede debutar en forma tardía (varios años), o en forma aguda, caracterizándose por ictericia (25\%), fiebre, dolor abdominal o malestar general $(10 \%)^{17}$.

Hepatitis $C$ en el embarazo: no se ha demostrado que la gestación modifique el curso de la infección aguda o crónica o la haga progresar más rápidamente. La gran mayoría de las mujeres embarazadas con infección por VHC son portadoras de una hepatitis crónica por VHC clínica o subclínica adquirida muchos años previos al embarazo, aunque $1 \%$ puede adquirir la infección durante la gestación. En E.U.A. nacen anualmente alrededor de 40.000 hijos de madres portadoras de VHC. En Chile no existen cifras oficiales, pero si consideramos una incidencia semejante a los países desarrollados, debiera haber aproximadamente 2.570 nacimientos de madres con 
VHC (257.000 nacimientos anuales, aproximadamente).

Transmisión vertical: anti-VHC en un hijo de madre portadora, más allá del año de vida. La tasa de infección perinatal varía desde $1,7 \%$ en portadoras de VHC hasta $19-20 \%$ en portadoras de $\mathrm{VHC}$ y $\mathrm{VIH}^{3,24}$, con un promedio aproximado de 5 a 10\%. En mujeres ARN-VHC (-) las tasas de TV son de 1 a 3\%, aumentando a 4 a $6 \%$ en embarazadas con ARN-VHC $(+)^{25}$. La transmisión puede ser durante el embarazo o al momento del parto, siendo este último el más frecuente, debido al escaso paso transplacentario del virus y a la exposición a fluidos hemáticos contaminados maternos durante el parto. El mecanismo exacto de infección al feto se desconoce; no obstante, se destacan diversos factores de riesgo que favorecen la transmisión de una madre portadora de VHC al hijo, dentro de ellos factores de riesgo generales como: niveles altos de ARN de VHC en suero materno, asociación de infección por $\mathrm{VIH}$, uso de drogas endovenosas y antecedente de transfusión de sangre y factores de riesgo obstétrico: como membranas rotas por más de 6 horas, exposición del feto durante el parto a sangre materna (parto instrumental, sangrado excesivo, desprendimiento de placenta), procedimientos invasores con riesgo teórico de transmisión como la amniocentesis o cordocentesis (riesgo aún no demostrado), parto anterior con transmisión de VHC al RN y lactancia materna ${ }^{23-25}$.

Con respecto a la vía del parto, aunque algunos recomendaban la vía alta por el supuesto mayor riesgo de contagio por las membranas rotas ${ }^{3,26}$, la evidencia actual no ha logrado demostrar beneficio de la cesárea sobre el parto vaginal ${ }^{24,25}$. En caso de co-infección con VIH, la vía de resolución del parto será la recomendada en el protocolo nacional de manejo del VIH (Rev Chil Infect 2010; 27 (4): 364), no siendo modificado por la asociación a VHC.

La lactancia materna, a pesar de permitir paso de virus hacia el neonato, transfiere una carga viral tan baja que no es capaz de producir una infección activa, no estando por lo tanto contraindicada. Se deben tomar precauciones en caso de existir erosiones en el pezón, por el mayor paso de virus por la sangre. La asociación de VHC con VIH se considera una contraindicación de lactancia materna por el riesgo cierto de transmitir este segundo agente ${ }^{23}$.

La pesquisa prenatal de las mujeres portadoras de VHC en forma de tamizaje universal no está justificada, dada la baja incidencia en el embarazo $(1 \%)$ en países desarrollados. En Chile no se dispone de la incidencia de VHC en mujeres embarazadas, siendo de criterio del médico tratante el realizar estudio serológico en pacientes con factores de riesgo de contagio. Por lo tanto, es necesario conocer las indicaciones ${ }^{25}$ en las cuales se debe realizar: antecedente de transfusión de productos sanguíneos, uso de drogas endovenosas, antecedente de infección por VIH, antecedente de múltiples parejas sexuales, trabajadoras sexuales, aumento inexplicado de transaminasas hepáticas, paciente en hemodiálisis y pareja con infección por $\mathrm{VHC}$

Diagnóstico en la mujer embarazada: la infección en la mujer gestante se establece por detección de anticuerpos tipo IgG anti-VHC. Un método diagnóstico cualitativo es la determinación por RPC para ARN-VHC en suero, siendo esto un examen de alto costo, y por lo tanto, subutilizado. La determinación de la carga viral por RPC cuantitativa confiere utilidad en la mujer embarazada, ya que es un parámetro a considerar en el cálculo de riesgo de TV. Con respecto al recién nacido hijo de madre con la enfermedad, en diversos países aún no hay consenso con respecto al momento ideal para realizar le detección en suero de anticuerpos anti $\mathrm{VHC}^{27}$; sin embargo, en Chile la serología se determina no antes de los 15 meses de vida para evitar la detección de anticuerpos maternos en la sangre del lactante. Algunos autores plantean realizar la detección durante el primer año de vida, en al menos dos oportunidades; ARN-VHC en suero del lactante y anticuerpos anti-VHC a los 18 meses de vida ${ }^{24}$, o seguimiento con RPC para ARN de VHC al mes de vida y si este es negativo, a los 6 meses y al año de vida.

Prevención y tratamiento: actualmente no existe una vacuna efectiva para la prevención de hepatitis $\mathrm{C}$ debido a su rápida mutación y gran variedad de genotipos. En mujeres en edad fértil que están en tratamiento por hepatitis C crónica (asociación de ribavirina e interferón $\alpha$ por 6 a 12 meses) que se embarazan, se sugiere control estricto de la gestación y continuar terapia posterior al puerperio ${ }^{25,28}$. El tratamiento durante el embarazo con interferón y/o ribavirina está contraindicado por los potenciales efectos neurotóxicos y teratogénicos respectivamente, aunque evidencia actual no ha logrado determinar un daño directo con el uso del primero ${ }^{17,28}$. Por esto, en caso de detectar una hepatitis $\mathrm{C}$ aguda durante la gestación, el tratamiento debe diferirse hasta el período de puerperio tardío.

Un reporte reciente ${ }^{29}$ demostró que al detectar la infección en el tercer trimestre y diferir el tratamiento para el puerperio, logró disminuir la carga viral pero no impidió la evolución a la cronicidad en el RN.

\section{Virus de hepatitis D}

Generalidades: es un virus ARN pequeño de $35 \mathrm{~nm}$, de replicación defectuosa, por lo que requiere su asociación con HBsAg para producir infección y replicar.

Epidemiología: la prevalencia es variable alrededor del mundo, con cifras que varían desde 1 a $10 \%$ en países como E.U.A., hasta 20 a $40 \%$ en países de África y Medio Oriente ${ }^{1}$.

Vía de contagio: se produce por vía parenteral (Tabla 1) de dos maneras: como co-infección con VHB o sobreinfección en paciente portador de VHB. 
Período de incubación: se describen períodos que van de 4 a 7 semanas.

Manifestaciones clínicas: puede presentarse con síntomas agudos inespecíficos como ictericia, dolor abdominal, fiebre, malestar general, o como una reagudización o exacerbación en un paciente portador de $\mathrm{VHB}^{3}$. Aproximadamente portadores crónicos de $\mathrm{VHB}$ sobreinfectados con virus de hepatitis D (VHD) de los cuales $70-80 \%$ desarrollarán cirrosis, cifra muy superior al $15 \%$ observado en la infección única por VHB.

Hepatitis $D$ en el embarazo: la infección por VHD en la gestación no ha demostrado ser más grave que en la paciente no embarazada; sin embargo, la detección de esta entidad debe estudiarse ante una mujer embarazada con diagnóstico de VHB aguda o crónica que presenta una reagudización del cuadro, mediante la detección de anticuerpos anti-VHD en suero materno.

Transmisión vertical: no se ha descrito la presencia de transmisión vertical, por lo que los hijos de portadoras de VHD no requieren de tamizaje al nacer, a menos que se asocie a VHB. La lactancia materna no está contraindicada. La transmisión materno-fetal del VHD es excepcional y puede evitarse con la inmunoprofilaxis para la VHB en el neonato ${ }^{30}$.

Diagnóstico en la mujer embarazada: ante la sospecha en la madre, debe determinarse anticuerpos anti-VHD del tipo IgM, siempre asociado a determinación de VHB. Sin embargo, en el caso del hijo, la detección de anticuerpos en suero no es justificada a menos que exista co-infección de la madre con VHB. El diagnóstico debe sospecharse en pacientes con HBsAg $(+)$ que empeoran su condición clínica en forma repentina.

Prevención y tratamiento: debido a su baja incidencia y asociación exclusiva con VHB, no existe un tratamiento específico para el VHD. Ante la detección en el embarazo, se debe manejar exclusivamente la co-infección con VHB según lo mencionado anteriormente (ver sección Virus de hepatitis B).

\section{Virus de hepatitis $\mathbf{E}$}

Generalidades: virus ARN de tamaño pequeño, perteneciente a la familia Calicivirus ${ }^{1,3}$, causa una infección generalmente benigna y autolimitada con excepción de la primoinfección durante el embarazo, donde puede evolucionar a hepatitis fulminante ${ }^{31-33}$. La infección con virus hepatitis $\mathrm{E}$ (VHE) no evoluciona hacia la cronicidad (Tabla 1).

Epidemiología: las zonas de mayor prevalencia en el mundo se concentran en México y países de Asia y África, siendo en estas áreas la principal causa de hepatitis fulminante y hepatitis aguda esporádica ${ }^{31}$. En países desarrollados, la infección es adquirida por viaje a países endémicos. En Chile se describe una prevalencia intermedia de 4 a $8 \%{ }^{13}$. Se caracteriza por afectar predominantemente al adulto joven y por presentar una evolución autolimitada. Se describen tasas de mortalidad menores de $0,1 \%{ }^{32}$. Sin embargo, en mujeres gestantes estas tasas aumentan dramáticamente hasta 20 y $40 \% .{ }^{1}$ En países de alta incidencia, la infección por VHE aumenta durante el embarazo, hecho que fuera demostrado en una publicación que evidencia tasas de incidencia de $2,1 \%$ en la mujer no gestante versus $18 \%$ en mujeres embarazadas en tercer trimestre ${ }^{31}$. En la actualidad sigue siendo desconocida la razón de la mayor incidencia y gravedad de esta infección en la mujer embarazada ${ }^{33}$.

Vía de contagio: se adquiere por transmisión fecal-oral al consumir aguas contaminadas ${ }^{3,31-33}$, motivo por el cual es más frecuente en países en vías de desarrollo donde el acceso al agua potable es más escaso.

Período de incubación: se describe de 2 a 9 semanas ${ }^{1,3}$, pudiendo detectarse el ARN de VHE hasta dos semanas posteriores al inicio de los síntomas.

Manifestaciones clínicas: puede presentar síntomas inespecíficos leves o moderados, siendo asintomático en 2/3 de los infectados. Los síntomas son ictericia, fiebre y dolor abdominal. En la mujer gestante puede debutar con un cuadro grave como hepatitis fulminante ( 20 veces más riesgo que la no gestante) ${ }^{3}$.

Hepatitis E en el embarazo: En países subdesarrollados, con altas prevalencia de infección, el VHE es la principal causa de hepatitis aguda fulminante en la mujer embarazada, siendo este agente etiológico el responsable de aproximadamente la mitad de todas las hepatitis agudas virales ${ }^{33}$. La razón que explicaría el porqué la gestante es más susceptible a realizar una evolución tórpida de $\mathrm{VHE}$ es desconocida, pero se ha planteado que estaría basada en la disminución de la respuesta inmune celular (Th-1) al parecer secundaria a los altos niveles de hormonas esteroídeas que inducirían cambios inmunológicos, los cuales influirían sobre la expresión y replicación viral durante el embarazo ${ }^{32,34}$. Esto último ha sido demostrado en una reciente publicación en la que se estudiaron el recuento plasmático de células CD4, CD8 y la relación de ambos (CD4/CD8) en mujeres gestantes que cursaron con hepatitis fulminante versus mujeres controles no embarazadas, concluyendo que existía una disminución del recuento de células CD4, un aumento de células CD8 y una disminución de la relación CD4/CD8 en las gestantes, todos valores con significancia estadística ${ }^{34}$.

La infección por VHE durante el embarazo se ha relacionado con mal pronóstico obstétrico, es así que se han evidenciado mayores tasas de aborto, muerte fetal y parto prematuro. Las tasas de mortalidad por hepatitis fulminante aumentan a medida que progresa la gestación, alcanzando los valores más altos durante el tercer trimestre con cifras que bordean el 44 a $50 \%{ }^{3,31}$. Diversas experiencias han demostrado que la incidencia de hepatitis 
fulminante por VHE aumenta desde $16 \%$ en el primer trimestre hasta $51 \%$ en el segundo y tercer trimestre ${ }^{35,36}$.

Debido a lo anterior, esta infección debe considerarse en el diagnóstico diferencial de patologías que evolucionan con falla hepática fulminante durante el embarazo como son el hígado graso agudo y el síndrome de HELLP.

Transmisión vertical: se describen TV en 33 a $50 \%$ de $\operatorname{los} \operatorname{casos}^{36}$, no quedando aún definido el mecanismo exacto de transmisión. En el recién nacido puede producir una hepatitis aguda sintomática que puede conducirle a la muerte por falla hepática fulminante durante las primeras 24 horas de vida. Un estudio reciente demostró $79 \%$ de infección perinatal en hijos de madres con VHE (detectado por presencia de IgM anti VHE en el RN), falleciendo aproximadamente $50 \%$ de ellos a la semana de vida. Un $15 \%$ evidenció traspaso de anticuerpos maternos vía transplacentaria, basado en la presencia de $\mathrm{IgG}$ anti VHE determinado al nacer ${ }^{37}$. La lactancia materna no está contraindicada ${ }^{3,36}$.

Diagnóstico en la mujer embarazada: tanto en la madre como en el recién nacido es fundamental la clínica, en busca de signos como ictericia, fiebre aumento de las transaminasas, hepatomegalia y sensibilidad hepática. Siempre es importante considerar el antecedente de viajes a zonas endémicas o el contacto con aguas contaminadas en la anamnesis. La infección por VHE debe sospecharse en toda mujer sintomática con pruebas negativas para VHA, VHB y VHC. Debido a la corta duración del IgM en el suero del afectado, la detección de IgG anti VHE es el único parámetro útil para el diagnóstico, a causa de su aparición rápida y permanecer elevado en el tiempo. ${ }^{38}$ También es de utilidad la determinación de ARN VHE por RPC. Sin embargo, debido al mayor costo de este examen, no es utilizado regularmente.

Prevención y tratamiento: actualmente no existen vacunas o inmunoglobulinas que eviten o aminoren la patología ni sus complicaciones ${ }^{36}$. Está en desarrollo una vacuna anti hepatitis $\mathrm{E}$ (fase 3 ) que ha demostrado ser efectiva tanto en hombres como en mujeres. Sin embargo, aún falta evaluarla en el tiempo, no habiendo estudios en mujeres embarazadas ${ }^{39}$.

\section{Discusión}

La hepatitis aguda es una de las enfermedades hepáticas más comunes durante el embarazo, su etiología es fundamentalmente viral, originada por virus hepatotropos. Es una de las causas más importantes de ictericia durante la gestación; sin embargo, la evolución y gravedad del cuadro clínico no se ven influenciadas por éste, salvo cuando es producida por el VHE. En este último caso, la incidencia de hepatitis fulminante es mayor y la morbimortalidad del binomio madre-hijo aumenta a medida que progresa el embarazo.
La hepatitis viral en el embarazo es una entidad que debe considerarse al enfrentar una paciente embarazada con o sin ictericia, fiebre, compromiso del estado general, con pruebas de función hepática alteradas o alteraciones hematológicas inespecíficas (trombocitopenia, leucopenia) e incluso en cuadros dramáticos como encefalopatía, ya que a pesar de su baja incidencia presenta complicaciones de grado variable, de acuerdo al virus involucrado ${ }^{40,41}$.

Es fundamental conocer los distintos factores de riesgo que favorecen las distintas infecciones por virus de hepatitis para promover las medidas necesarias para su prevención. Dentro de estas medidas debe destacarse la educación en la manipulación de alimentos (prevención de hepatitis A y E), vida sexual responsable (prevención de hepatitis B y C) y la integración de vacunas dentro del programa nacional de inmunización (hepatitis A y B). En el caso de la hepatitis C, donde no existe vacuna disponible, es importante pesquisar gestantes portadoras en la población de mayor riego (usuarias de drogas endovenosas, con antecedente de transfusiones de hemoderivados o hemodializadas, etc) con el fin de diagnosticar una probable transmisión vertical y eventualmente seguir su evolución ${ }^{17}$.

A pesar de la mayor frecuencia de los distintos virus hepatotropos anteriormente mencionados en la producción de hepatitis en la mujer embarazada, es prudente recordar también al virus herpes simplex (VHS) tipo 2 que, a pesar de su baja prevalencia en mujer embarazada (1/2.500-1/5.000 partos), durante su primoinfección puede evolucionar a una hepatitis aguda. Además del grave compromiso del estado general, este cuadro se caracteriza por la presencia de lesiones orales o vulvares y por el impacto que produce la infección a nivel intrauterino (mayor riesgo de aborto, óbito, lesiones cutáneas, oftalmológicas y neurológicas en el neonato ${ }^{41}$. Frente a la sospecha diagnóstica y ante la gravedad del cuadro la utilización de aciclovir ha demostrado ser útil en el control del impacto de la enfermedad en el binomio madre-hijo.

Sólo existe tratamiento o profilaxis en el caso de VHA, VHB y VHS. En el resto de los virus no existen medidas aplicables, salvo la prevención de la infección.

\section{Resumen}

La hepatitis aguda es una enfermedad de baja incidencia durante el embarazo; sin embargo, es una causa importante de ictericia durante el desarrollo de éste y en algunos casos presenta un alto riesgo de morbi-mortalidad materno-fetal, siendo la etiología principalmente viral. El propósito de este artículo es actualizar los conocimientos disponibles en la literatura médica respecto a hepatitis viral durante el embarazo, conocer cuáles son los agentes más prevalentes, vía de transmisión, riesgo para el binomio madre- hijo y eventual manejo. 


\section{Referencias}

1.- Cotran R, Kumar V, Collins T. Robbins: Patología Estructural y Funcional. 2000. Sexta edición. Editorial McGraw Hill Interamericana: 893-904.

2.- Consultado en www.minsal.cl el 10/10/2009.

3.- Hutto C. Congenital and Perinatal Infections. A Concise Guide to Diagnosis. Hepatitis Viruses Chapter 15 Editorial Humana Press 2006: 169 179

4.- Medina B, Olea A, Aguilera X. Situación epidemiológica de hepatitis A en Chile. Rev Chil Infect 2003; 20 (4): 262-7.

5.- Motte A, Blanc J, Minodier P, Colson P. Acute hepatitis $A$ in a pregnant woman at delivery. Int J Infect Dis 2009; 13: e49-e51.

6.- Kudo M. Viral hepatitis A to E: An update in 2010. Intervirology 2010; 53: 5-9.

7.- Selander B, Blackberg J, Widell A, Johansson P. No evidence of intrauterine transmission of hepatitis A virus from a mother to a premature infant. Acta Paediatrica 2009; 98: 1603-6.

8.- Bruguera M. Prevention of viral hepatitis. Enferm Infecc Microbiol Clin 2006; 24 (10): 649-56.

9.- Gruslin A, Steben M, Halperin S, Money D, Yudin M. Immunization in pregnancy. J Obstet Gynaecol Can 2008; 30 (12): 1149-54.

10.- Ferreira C, Silveira T. Viral hepatitis prevention by immunization. J Pediatr (Rio de J) 2006; 82 (3): s55-s66.

11.- Cofré J, Abarca K. Vacuna anti hepatitis A. Rev Chil Infect 2003; 20 (4): 243-52.

12.- Chang M. Hepatitis B virus infection. Semin Fetal Neonatal Med 2007; 12: 160-7.

13.- Ibarra H. Cambios en la epidemiología de las hepatitis virales en Chile y consideraciones en estrategias de prevención. Rev Méd Chile 2007; 135: 229-39.

14.- Poland G, Jacobson R. Prevention of hepatitis $B$ with the hepatitis B vaccine. N Engl J Med 2004; 351 (27): 2832-8.

15.- Hieber JP, Dalton D, Shorey J, Combres B. Hepatitis and pregnancy. J Pediatr 1977; 91: 545-9.

16.- Wang Z, Zhang J, Yang H, Li X, Wen S, Guo Y, Sun J, Hou J. Quantitative analysis of HBV DNA level and $\mathrm{HBeAg}$ titer in hepatitis B surface antigen positive mothers and their babies: HBeAg passage through the placenta and the rate of decay in babies. J Med Virol 2003; 71: 360-6.

17.- Panda B, Panda A, Riley L. Selected viral infections in pregnancy. Obstet Gynecol Clin N Am 2010; 37: 321-31.

18.- Xu Q, Xiao L, Lu X, Zhang Y, Cai X. A Randomized controlled trial: interruption of intrauterine transmission of hepatitis B virus infection with HBIG. World J Gastroenterol 2006; 12 (21): 3434-7.

19.- Li X, Yang Y, Hou H, Shi Z, Shen H, Teng B, Li A, Shi M, Zou L. Interruption of HBV intrauterine transmission: a clinical study. World J Gastroenterol 2003; 9 (7): 1501-3.

20.- Xu W, Cui Y, Wang L, Yang H, Liang Z, Li X, Zhang S, et al. Lamivudine in late pregnancy to prevent perinatal transmission of hepatitis B virus infection: a multicentre, randomized, double blind, placebo-controlled trial. J Viral Hepatitis 2009; 16: 94-103.

21.- Xiao X, Li A, Chen X, Zhu Y, Miao J. Prevention of vertical hepatitis B transmission by hepatitis B immunoglobulin in the third trimester of pregnancy. Int J Gynecol Obstet 2007; 96: 167-70.

22.- Sami Sh, Korejo R, Bhutta Sh. Prevalence of hepatitis B and C: A Jinnah Postgraduate Medical Centre experience. J Obstet Gynaecol Res 2009; 35 (3): 533-8.

23.- Mast E, Hwang L, Seto D, Nolte F, Nainan O, Wurtzel H, Alter M. Risk factors for perinatal transmission of hepatitis $\mathrm{C}$ virus (HCV) and the natural history of $\mathrm{HCV}$ infection acquired in infancy. J Infect Dis 2005; 192: 1880-9.

24.- Indolfi G, Resti M. Perinatal transmission of hepatitis C virus infection. J Med Virol 2009; 81: 836-43.

25.- Airoldi J, Berghella V. Hepatitis C and pregnancy. Obstet Gynecol Surv 2006; 61 (10): 666-72.

26.- European Pediatric Hepatitis C Virus Network. Effects of mode of delivery and infant feeding on the risk of mother-to-child transmission of hepatitis C virus. Br J Obstet Gynecol 2001; 108: 371-7.

27.- Dinsmoor MJ. Hepatitis in the obstetric patient. Infect Dis Clin North Am 1997; 11: 77-91.

28.- Ozaslan E, Yilmaz R, Simsek H, Tatar G. Interferon therapy for acute hepatitis $\mathrm{C}$ during pregnancy. Ann Pharmacother 2002; 36: 1715-8.

29.- Gonzalez F, Meda-Djomo M, Lucidarme D,
Khalil A, Decoster A, Houze D, Filoche B. Acute hepatitis $\mathrm{C}$ during the third trimester of pregnancy. Gastroenterol Clin Biol 2006; 30: 786-9.

30.- Ranger-Rogez S, Alain S, Denis F. Hepatitis viruses: mother to child transmission. Pathol Biol (Paris). 2002; 50 (9): 568-75.

31.- Begun N, Kumar S, Akhtar S, Kumar A, Kar P. Duration of hepatitis E viremia in pregnancy. Int J Gynecol Obstet 2009; doi:10.1016/j. ijgo.2009.09.023.

32.- Navaneethan U, Mohajer M, Shata M. Hepatitis E and pregnancy - understanding the pathogenesis. Liver Int 2008; 28 (9): 1190-9.

33.- Khuroo M. S, Kamili S. Aetiology, clinical course and outcome of sporadic acute viral hepatitis in pregnancy. J Viral Hepatitis 2003; 10: 61-9.

34.- Jilani N, Das BC, Husain SA, Baweja UK, Chattopadhya D, Gupta RK, et al. Hepatitis E virus infection and fulminant hepatic failure during pregnancy. J Gastroenterol Hepatol 2007; 22 (5): 676-82.

35.- Jaiswal S P B, Jain A K, Naik G, Soni N, Chitnis D S. Viral hepatitis during pregnancy. Int J Gynecol Obstet Vol 2001; 72 (2): 103-8.

36.- Sookoian S. Liver disease during pregnancy: acute viral hepatitis. Ann Hepatol 2006;5 (3): 231-6.

37.- Khuroo M.S, Kamili S. Clinical course and duration of viremia in vertically transmitted hepatitis $E$ virus (HEV) infection in babies born to HEV-infected mothers. J Viral Hepatitis 2009; 16: 519-23.

38.- Hurtado C, Muñoz G, Brahm J. Anti-VHE IgM en casos de infección por el virus hepatitis $\mathrm{E}$. Rev Méd Chile 2005; 133: 645-7.

39.- Zhu F, Zhang J, Zhang X, Zhou C, Wang Z, Huang $S$, et al. Efficacy and safety of a recombinant hepatitis $\mathrm{E}$ vaccine in healthy adults: a large-scale, randomised, double-blind placebo-controlled, phase 3 trial. The Lancet, Early Online Publication, 23 August 2010. doi:10.1016/S0140-6736(10)61030-6.

40.- Norvell J, Blei, Jovanovic B, Levitsky J. Herpes simplex virus hepatitis: An analysis of the published literature and institutional cases. Liver Transplant 2007; 13:1428-34.

41.- Nelson-Piercy C. Handbook of Obstetric Medicine. Isis Medical Media Ltda First edition 1997 Capítulo:161 pg 164. 